\title{
Implementation of lung cancer multidisciplinary teams: a review of evidence-practice gaps
}

\author{
Nicole M. Rankin ${ }^{1}$, Elizabeth A. Fradgley ${ }^{2,3,4}$, David J. Barnes ${ }^{1,5}$ \\ ${ }^{1}$ Faculty of Medicine and Health Sciences, University of Sydney, Camperdown, New South Wales, Australia; ${ }^{2}$ University of Newcastle Priority \\ Research Centre for Cancer Research, Innovation and Translation, Callaghan, New South Wales, Australia; ${ }^{3}$ University of Newcastle Priority \\ Research Centre for Health Behaviour, Callaghan, New South Wales, Australia; ${ }^{4}$ School of Medicine \& Public Health, University Drive, Callaghan, \\ New South Wales, Australia; ${ }^{5}$ Sydney Local Health District, Royal Prince Alfred Hospital, Camperdown, New South Wales, Australia \\ Contributions: (I) Conception and design: All authors; (II) Administrative support: None; (III) Provision of study materials or patients: None; (IV) \\ Collection and assembly of data: NM Rankin; (V) Data analysis and interpretation: All authors; (VI) Manuscript writing: All authors; (VII) Final \\ approval of manuscript: All authors. \\ Correspondence to: Nicole M. Rankin, PhD. Research in Implementation Science and e-Health (RISe), Faculty of Medicine and Health Sciences, \\ UNIVERSITY OF SYDNEY. Charles Perkins Centre (D17), Johns Hopkins Drive (off Missenden Road), Camperdown, NSW 2006, Australia. \\ Email: nicole.rankin@sydney.edu.au.
}

\begin{abstract}
Multidisciplinary care (MDC) is considered best practice in lung cancer care. Health care services have made significant investments in MDC through the establishment of multidisciplinary team (MDT) meetings. This investment is likely to be sustained in future. It is imperative that MDT meetings are efficient, effective, and sufficiently nimble to introduce new innovations to enable best practice. In this article, we consider the 'evidence-practice gaps' in the implementation of lung cancer MDC. These gaps were derived from the recurrent limitations outlined in existing studies and reviews. We address the contributions that implementation science and quality improvement can make to bridge these gaps by increasing translation and improving the uptake of innovations by teams.
\end{abstract}

Keywords: Implementation science; lung cancer; multidisciplinary care (MDC); quality outcomes

Submitted Sep 02, 2019. Accepted for publication Nov 25, 2019.

doi: $10.21037 /$ tlcr.2019.11.32

View this article at: http://dx.doi.org/10.21037/tlcr.2019.11.32

\section{Introduction}

Multidisciplinary care (MDC) is considered best practice in cancer. This model of care is an integral component of coordinated cancer care in many health care settings $(1,2)$ and is considered essential in patient-centred care frameworks (3-7). A multidisciplinary approach to lung cancer care is also highly applicable given the complexities of diagnosis and treatment of the disease.

Published studies use the terms MDC, multidisciplinary teams (MDT) meetings (or tumor boards) interchangeably; this is often without providing definitions or describing distinguishing features (8). In this review article, we focus on MDC specifically for lung cancer and use the following definitions. MDC is defined as focusing on 'an integrated team approach to health care' where the team will use various means of communicating about patient care (9). MDT meetings facilitate MDC and are defined as 'an alliance of medical and health care professionals related to a specific tumor disease whose approach to cancer care is guided by their willingness to agree on evidence-based clinical decisions and to co-ordinate the delivery of care at all stages of the process' $(10,11)$.

In most settings, medical and nursing specialists are the 'core' team who participate in MDT meetings, usually with limited contributions from allied and supportive care health professionals, or primary and community care (12). A quorum of allied health sub-specialities is often required to be attendance at MDT meetings. There are significant variations in how models are applied across health services 
and the composition of MDTs (13). It has been noted that MDT meetings were initially established without a strong evidence base (14). However, with several hundred studies now published in the area, there is evidence to demonstrate that a team approach provides benefits to patients, results in improved clinical and process outcomes (15), enables greater cooperation and communication across medical professionals and opportunities for professional development.

Studies about MDT meetings have examined various aspects such as: descriptions of their organisation, functioning, documentation and process outcomes (16-18); positive impact on clinical outcomes $(19,20)$; receipt of treatments in accordance with clinical practice guidelines or quality indicators $(21,22)$; quality assurance and the role of evidence in treatment recommendations (23); information sharing and communication within the team (24-26), including reciprocal team peer review $(27,28)$; communication with primary care providers (29); patient engagement and patient exclusion from meeting processes (30-33); barriers to clinician participation and implementation of treatment plans $(34,35)$; and the influence of policy and costs (36,37). MDC also offers an opportunity for patient recruitment into clinical trials $(38,39)$. A number of systematic and scoping reviews have summarised these aspects $(11,15,40-42)$. Our review does not seek to address the topic of survival, as this can be found in other publications (see article by S Vinod in this journal issue).

MDC and the commitment to MDT meetings is likely to be sustained over time because of the significant investment made by health care services and clinicians, along with the strong support of patients and consumer organisations. Given the substantial 'buy-in' and the inherent opportunity cost of this clinical activity, it is imperative that MDT meetings are efficient, effective, and sufficiently nimble to introduce new innovations to enable best practice.

The aim of this paper is to consider the 'evidence-practice gaps' in the implementation of lung cancer MDC. These gaps were derived from the recurrent limitations outlined in existing studies and reviews, and by conducting a synthesis of the future research directions proposed in systematic reviews, intervention and descriptive studies, as well as commentaries. We address the contributions that quality improvement and implementation science could potentially make to bridge these gaps by increasing translation and improving the uptake of innovations by teams. We conclude with potential directions for future research focused on improving the effectiveness of MDT meetings.

\section{Methods}

We identified a number of existing systematic reviews $(11,15,40,41,43,44)$ and scoping reviews $(45)$ about lung cancer and/or MDC. Due to the recency of the field and the limited scholarship specific to lung-cancer (39), seminal research in other cancer types was included where relevant. We examined each review for nominated evidence-practice gaps. The scope did not extend to reviewing the extensive literature of all systematic reviews across multiple tumor streams nor use systematic literature review methods. A narrative review was deemed the most appropriate approach to collate and summarise the heterogeneous literature base related to both implementation science and MDC in lung cancer. As part of the review process, we conducted an update of the literature identified in the Pillay et al.'s review (11), replicating the search terms and extending the search period from April 2015 to December 2018. As a result, an additional 45 articles were identified, of which 17 were specific to lung cancer (45-61). We also reviewed references to identify seminal studies by leading clinician-researchers for further review.

\section{Results}

\section{Identified gaps in multidisciplinary lung cancer care}

We identified numerous gaps and have grouped these according to the level of impact: patient, team and health service and system gaps. Across these levels, a number of fundamental research gaps and limitations were recurrent.

\section{Research and evaluation gaps}

\section{Lack of control condition}

Much of the MDC literature to date has focused on describing the processes, structures and outcomes of this model. The identified evidence-practice gap is reiterated as the need to establish a robust evidence base that can demonstrate the benefits of MDC over other standards of care $(11,40,62)$. This presents a significant challenge as MDC has become the standard of cancer care in many developed countries. Consequently, systematic reviews note a proliferation of descriptive research studies and that it is challenging to design randomised study designs to 'unpack' the complexity of MDC to demonstrate positive outcomes 
without an available control condition.

\section{Variation in definitions and outcome measures selected}

Many studies do not include definitions of the model of care being studied, which makes comparisons difficult to conduct. Furthermore, a wide variety of outcome metrics have been used to evaluate MDT meetings such as clinical outcomes (e.g., survival), process measures (e.g., proportion of treatment recommendations followed), and patient satisfaction (11). The field will struggle to compare, evaluate, and replicate research findings without operationalising the model of care and using standardised outcome measures for MDT meetings. A paradigm shift in both the design and reporting of research studies is required, along with greater attention being placed on defining the optimal MDT models needed in practice.

\section{Single-site studies}

The sample size and heterogeneity of MDT meetings also pose a barrier to conducting robust pragmatic trials. The majority of available evidence is derived from single-site studies that are likely to represent a limited snapshot of institution-specific workflows, resources, and patient groups within a limited catchment area (39). To compare the outcomes of MDT meetings for specific tumor types such as lung cancer, multi-centred studies that conduct extensive scoping of the characteristics of each individual MDT to ascertain baseline differences and similarities are required.

In summary, in order to bridge research and evaluation gaps there is an urgent need to support and fund pragmatic multi-centre trials that enable 'bench to bedside' translational research questions to be answered. Consensus on an operationalised definition for MDC and guidance on appropriate outcome measures for MDT meetings are also needed.

\section{Patient-related gaps}

\section{Patient-centred MDC}

Many studies about MDC highlight the need for greater engagement with patients and caregivers in both practice and research processes $(30-33,42,63)$. This includes practice-based considerations about how MDT meeting recommendations could impact shared decision making and if the process is guided by patient-centred care principles. For example, observational and self-reported data from a study of five MDT meetings (across different tumour groups) found patients' views and psychosocial issues were the least-commonly discussed when compared to case histories, radiological, and histopathological information (64). MDT meeting participants ( $\mathrm{n}=67$ clinicians, nurses and MDT coordinators) self-rated the content as being more patient-centred than the ratings from observers; this discrepancy suggests that MDT participants may struggle to critically reflect on the degree to which preferences and psychosocial issues are incorporated in practice (64). Observational data from another study of 15 MDT meetings suggested that even when patient treatment preferences were discussed, this information was seldom accounted for in treatment recommendations (63). Previous research strongly suggests MDT meeting recommendations that do not account for patients' preferences are less likely to be implemented (63). There is limited time allocated for each case and presentation of background knowledge about the patient. In light of this, the degree to which patientcentred care principles such as patient involvement and preferences can be incorporated in MDT meetings warrants further exploration.

\section{Patient evaluation of MDT meetings}

Along with consensus-driven clinical outcome measures and economic analyses, efforts to bridge implementation gaps should also include patient-related evaluation. This is a significant gap in knowledge of MDT processes with studies suggesting that patients may not be aware of being presented at an MDT meeting. Similarly, they may be unable to recall if their care was informed by teamconsensus. For example, a survey of Australian hospitals reported that approximately one in the three cancer patients were not informed their case was presented at an MDT meeting and either verbal or written consent was not documented (12). Of the 27 studies reviewed by Pillay et al., none evaluated how an MDT meeting influenced patient satisfaction or quality of life (11).

The limitations of the various patient-related measurement approaches must be carefully reviewed before incorporation into trial designs. Generic satisfaction tools are prone to ceiling effects, whereby the majority of patients will report high levels of positive experiences with their overall care, resulting in an inability to potentially hone in on specific areas of improvement within the data; furthermore insufficient data are collected to allow comparisons across patient groups $(65,66)$. Many patientexperience questionnaires also do not provide actionable data to improve the quality of care (67). At the most basic level, patients should be asked to comment on the 
acceptability of a team-based approach to their care; provided with information about how this model of care could be beneficial (such as increased confidence in treatment plans); whether it raises concerns (such as data privacy); and whether it impacts on their decision-making. The increasing awareness and testing of patient-reported outcome measures (PROMs) in cancer care may provide guidance on how MDTs could be evaluated from a patientperspective (68).

In summary, subsequent research should explore the impact of MDTs on patient-centred dimensions of care including shared decision-making. This requires patient perspectives to be collected in a systematic and comprehensive manner. Given the emphasis on pragmatic research, well-designed implementation trials could provide an invaluable opportunity to explore patient acceptability of MDC approaches through qualitative and quantitative data.

\section{Team-related gaps}

\section{Difficulties in reaching consensus}

A primary purpose of the MDT meeting is to generate consensus recommendations for each patient's treatment plan. Evidence about MDT effectiveness is based on nonrandomised studies and indicates that meetings positively impact on patient outcomes $(48,60,69)$. For example, an Australian study of about 1,000 patients showed that patients presented at MDT were more likely to receive treatments in accordance with clinical practice guidelines, including higher rates of treatment receipt for radiation therapy and chemotherapy (46). However, there is relatively little published about how meetings influence treatment recommendation outcomes (in comparison with any plan initially outlined by the coordinating clinician) and whether the administered treatments are implemented in concordance with the recommendations (42).

\section{Variation in selection of patients for team review}

A second gap in implementation is concerned with patient selection for meeting presentation. There is significant debate about whether all patients need to be reviewed in the setting of an MDT meeting and how MDC is offered outside the setting of a meeting; examples in other solid tumors include colorectal cancer $(36,70,71)$.

In lung cancer, there are significant variations in international approaches to patient selection. Perhaps the best-known example is the mandatory presentation of all patients in France (72). In other countries, most health systems do not give policy mandates; decisions about patient selection may be on the basis of agreed team protocols, discipline preferences (e.g., curative patients eligible for surgical treatment are first presented), complexity (e.g., Stage IIIA and B patients are reviewed first) (18). Agreement within the team about selection is also needed given the volume of patients; some teams will not be able to meet the demand to review all patients within a weekly meeting. Selection may also include presentation of challenging cases for educational purposes to encourage learning for junior clinicians. As many MDTs were established prior to research-informed guidelines, referral processes may not be outlined in existing term of references (73). Without established referral criteria, processes may differ substantially across and within MDTs as each clinician may differ in how their criteria about how best to select patients for MDT review. These variations present significant challenges in comparing the MDC outcomes, particularly if protocols are not documented, change over time or are not explicitly declared.

Thus, the implementation gap about patient selection requires studies that provide specific evidence about where the greatest benefit from MDT review might be realised; this might include specifying those strategies that enable implementation of a consistent referral pathway while supporting clinicians to manage a balance across patient benefit and educational cases. One strategy may be the use of audit and feedback to evaluate patient referrals and outcomes; however, audit and feedback studies are infrequently published in MDC peer-reviewed literature (74).

\section{Educational value of MDT meetings}

The benefits of the MDT meeting as an education tool that provides a training ground for junior clinicians has not been thoroughly investigated (75). There is a lack of detailed information about how MDT meetings might be designed to contribute to building skills for junior doctors, nurses or allied health professionals or, indeed, skill maintenance for more experienced clinicians. An international survey of American Society of Clinical Oncology members found an overwhelming percentage (96\%) of MDT participants agreed meetings have significant teaching value (76). Few single institution studies present data about proportions of cases presented for educational value (77). This gap indicates an untapped potential for research to better understand the value of MDTs as an integral educational resource in the clinical management of lung cancer. 


\section{Communication within MDT meetings}

The conceptualisation of an MDC approach provided by Soukup et al. emphasizes that individual clinician skill, team skill, environment, and patient factors all impact on quality of care (42). There is emerging evidence and guidance about how to improve and benchmark the interpersonal qualities of an MDT meeting (42). However, questions remain such as how to address the barriers to MDT implementation or quality improvement (35). These barriers include group dynamics such as decisional conflict, inertia or fatigue within MDT meetings. Strategies to improve communication in the multidisciplinary and hierarchical setting are also needed (42). A range of educational tools to assist in such tasks is summarised by Soukup et al. (42) Validated tools include observational rating scales, team evaluation and assessment scales, and quality improvement checklists and scales to facilitate clinical decision-making and the inclusion of patient preferences (42).

The MDT meeting chairperson is likely to play a large role in bridging communication gaps. The chairperson facilitates meeting discussion, often manages conflict, and provides clinical leadership in this time-constrained setting (78). This leadership may also include eliciting the views of meeting participants who may be hesitant to voice alternative opinions and a capable chairperson may be able to identify and prevent 'group think' (42). Group think occurs when a team seldom disagrees and individuals chose not to voice opinions counter to the collective opinion; it can be an indicator of poor team climate. More effective moderation of discussions has been identified as one of the most important strategies to improve meeting efficiency (76). Clinical leadership and change champions are acknowledged as an effective implementation strategy for creating change in health services (79). However, guidance is sparse on how to select for or provide training on these non-technical skills in the lung cancer setting (80).

\section{Health service and system gaps}

Gaps in how MDC is implemented, measured and reported at health service and system levels are evident in the lung cancer literature. In this section, we review the literature about quality indicators and cost. We conclude with innovations that could help facilitate improvements into routine care.

\section{Quality outcomes}

Literature about the measurement of quality outcomes in cancer services has evolved significantly in response to growing pressures to meet health care demands, provide quality care and demonstrate that interventions and models of care are cost effective. (81). The development and use of quality indicators (including performance and clinical indicators) in lung cancer has steadily increased in the past two decades. Quality indicators are defined as 'measurable elements of practice performance for which there is evidence or consensus that they can be used to assess the quality of care' (82). A significant investment to establish indicators in lung cancer management was undertaken in the Netherlands beginning in the mid2000s (83), and numerous countries have also pursued this work to raise quality standards (84-86). For many MDT meeting participants, clinical outcomes will be of particular importance. While international efforts to collect these data are laudable, there is a notable gap in reporting about how these indicators drive an agenda for change. This lack of reporting may be attributed to the information source- - for example, indicator data may be published at conferences or in the grey literature and not readily accessible.

\section{Lack of costing data}

The cost of MDT meetings presents another evidence gap in implementation. Internationally, MDT meetings operate across a variety of health care systems that vary in universal health care coverage and fee-for-service structures. Across these structures, there is limited information on the costvalue of MDT meetings (or MDC more generally). For instance, MDT meetings may represent better value through efficient use of clinicians' time or reduction in unnecessary tests or treatments for patients. However, these meetings also incur substantial salary costs for attendance and a significant amount of time spent in preparation and coordination (87). We were unable to locate any systematic reviews specific to lung cancer care that analysed the cost benefits or cost-savings of implementing MDC or team meetings. We therefore summarise relevant observational or intervention studies.

In 2010, Bjegovich-Weidman et al., reported on the development of a MDC in thoracic oncology, including a $9 \%$ increase in revenue over a 2 -year period that was attributed to retention of patients within the local health system (88). However, this study has significant limitations in that it does not report patient outcomes data. In 2015, Freeman et al. reported a significant difference $(\mathrm{P}<0.0001)$ in health care costs for patients treated within the MDC setting compared to non-MDC across 27 cancer centres 
in the United States (39). The greater costs in the nonMDC group were attributed to increased use of imaging investigations. More recently, a 2019 study of 297 patients with non-small cell lung cancer reviewed in a single-day clinic in one institution found a significant reduction in cost (23\%) compared to patients seen outside the clinic setting (89). Little information has been published about gaining patient consent and billing practices.

These studies about cost highlight a gap in implementation regarding the benefit of potential reductions in repeat testing, an issue has not been thoroughly investigated or reported in the literature. As cost data are typically generated from administrative datasets, there may be limited insights into MDC cost because of calculation methods. Greater research efforts in conducting economic analyses of MDC could provide reassurance for service managers and policy makers that this model of care contributes better use of funds across health systems.

\section{Examples of innovations focused on health service gaps}

The role of national lung cancer registries in reporting outcomes

One mechanism that holds significant promise for demonstrating the benefits of MDC is lung cancer registries, which are implemented at the national or jurisdictional level as part of a professional quality system (90-92). While registries are not a new innovation, the data generated is shifting from retrospective documentation of variations in outcomes to more active, contemporary reporting to enable clinical audits of practice (59). This use of outcomes data can focus more precisely on reporting of clinically-relevant items to improve patient outcomes (93). We highlight the example of the Dutch national lung cancer registry.

In 2018, Beck and colleagues reported on the Dutch Lung Cancer Audit, which builds on two decades of development of clinical practice guidelines, quality indicators and collecting clinical data across surgical, radiation and medical oncology disciplines $(93,94)$. Data are reported for treatment and quality outcomes, including MDC outcomes. For example, this includes the proportion of patients with NSCLC discussed at an MDT meeting either prior to commencing radiation therapy treatment (95\%) or post-operatively (97\%). The latter was a $15 \%$ increase from $82 \%$ in 2012 . However, the use of registry data is not without problems, with the authors noting significant barriers in reporting MDT outcomes due to data privacy and sharing of information.

\section{Innovation in MDT data collection}

The opportunity to introduce innovative technologies in MDC are emerging as part of broader initiatives such as Learning Healthcare Systems (95), which use operational and clinical information to drive health system change. For example, the use of dashboards for reviewing data has been trialled as one component of a transformational approach to the lung cancer Diagnostic Assessment Program in Ottawa (95). Digital health innovations as include development of a mobile app for scheduling cases in MDT meetings (96) have also been recently reported. As research into MDC matures, greater emphasis will likely be placed on developing innovations and interventions that will improve outcomes by using research methodologies from implementation science and quality improvement.

\section{Implementation science and bridging the gap in MDT research and practice}

What is implementation science and how does it differ from quality improvement?

Implementation science is an emergent discipline within the broader spectrum of translational research (97). It is defined as 'the scientific study of methods to promote the systematic uptake of research findings and other evidencebased practices into routine practice to improve the quality and effectiveness of health services. It includes the study of influences on healthcare professional and organisational behaviour' (98). Definitions and glossaries of terms help non-experts to navigate the distinctions between dissemination and implementation research and similar terms that are used across different settings (99-101). Research questions are typically focused on the 'how' 'why' and 'who' of implementation, rather than the creation and testing of new interventions (102).

Implementation research requires a strong evidence base that demonstrates the efficacy of an intervention, which warrants further scientific investigation and application in real-world settings (103). A goal of implementation science is to create generalizable knowledge that can be replicated across different settings and contexts $(101,102)$, where context is broadly defined as 'the environment or setting in which the proposed change is to be implemented' (104).

Implementation strategies are the set of techniques used to promote or enhance the adoption and integration of an intervention into routine practice (105). Strategies are often grouped to address specific identified barriers to implementation success (101). There are several 


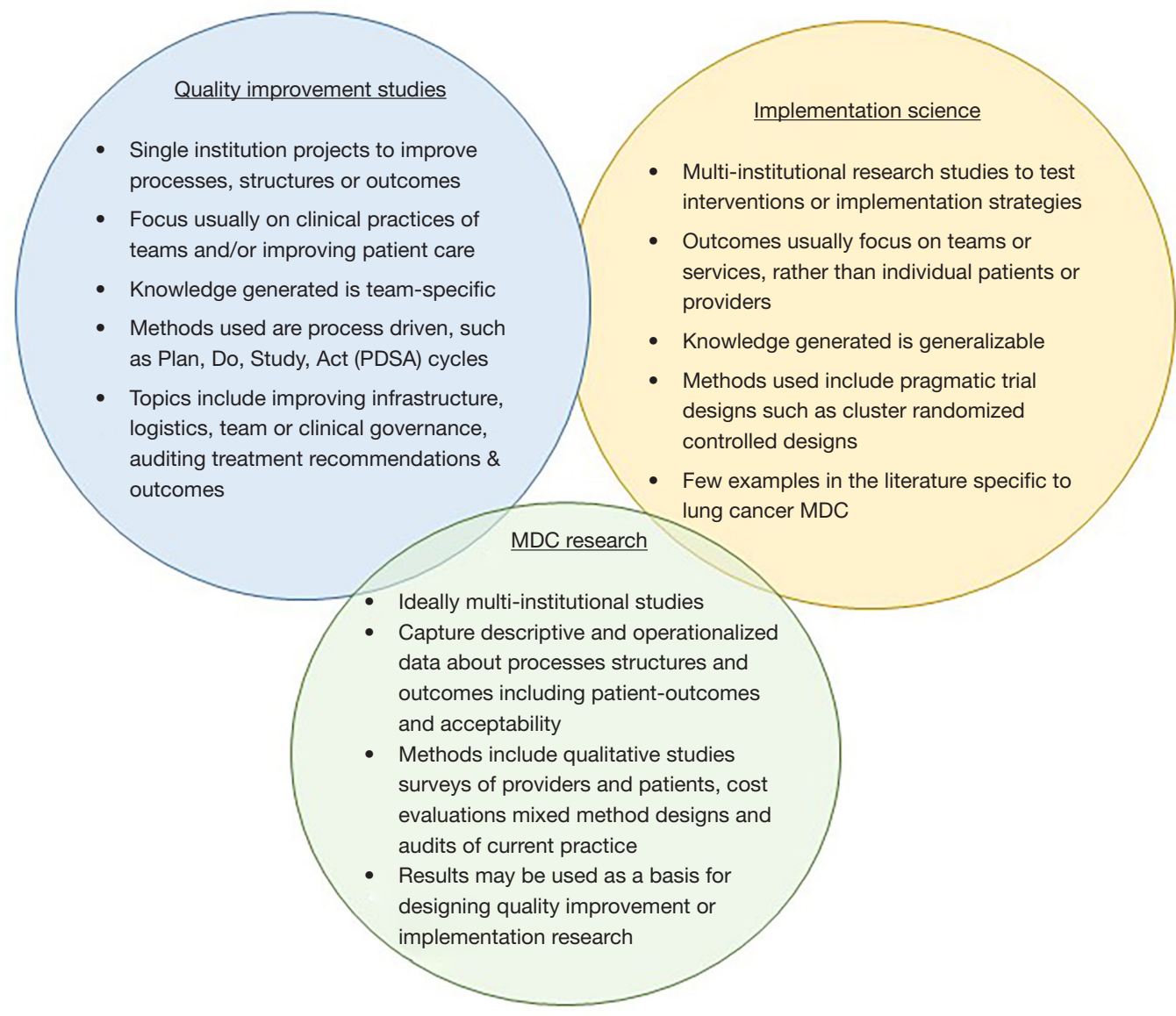

Figure 1 The intersection of implementation science, quality improvement and foundational research in lung cancer MDC. MDC, multidisciplinary care.

taxonomies that provide descriptive categories including educational, professional, financial, regulatory and organisational implementation (106-108). Examples of implementation strategies that target behaviour change in health professionals include audit and feedback, educational outreach, education meetings, printed educational materials, local opinion leaders, computerised reminders and tailored implementation strategies (109). These implementation strategies are all relevant for consideration in designing MDC research projects.

In contrast, quality improvement (QI) initiatives focus on making immediate improvements in health system performance and/or managing change in a single unit or hospital setting (102). QI methodologies were historically informed by process methodologies that originate in manufacturing; these methods use repeated cycles of change to address a specific problem. Examples include the Plan-Do-Study-Act (PDSA) cycle, which provides "a structure for iterative testing of changes to improve quality of systems" (110). Similarly, 'Lean' processing originated in Japan from Toyota and focuses on eliminating wasteful activities (e.g., waiting times, duplication of tests) to improve outcomes (111). While QI initiatives are highly relevant to MDC practice, these approaches may offer limited insights about how to successfully implement an innovation across multiple teams, as many studies appear to only be effective in specific settings $(110,112)$. Figure 1 shows the intersection across implementation science, QI and foundational research in lung cancer MDC.

\section{Implementation science-what is the relevance for MDT meetings and MDC?}

Implementation science is increasingly being recognised as 
one approach to building the evidence base in lung cancer MDC $(13,113)$. Implementation research requires effective collaboration across multiple disciplines of clinicians and researchers with expertise in health services research, health economics or behavioural science. Clinicianresearchers interested in exploring questions about lung cancer MDC may have limited access or contact with these diverse disciplines to optimise the design and conduct of implementation research studies (114).

\section{What is required to close the implementation gaps?}

Future implementation research should focus on testing strategies across multiple MDTs and/or multiple hospitals or health systems to simultaneously generate evidence about MDT effectiveness and implementation outcomes. We contend that the focus should be on behavior change, with a foundation in relevant theories and collaboration that engages key stakeholders such as MDT members, intervention developers, patients and health service managers. While there is limited evidence that collaboration results in sustainable change in health services, engagement with stakeholders as being increasingly recognised as part of quality research methodology (115). We draw on our team's example of adapting a local generic template to improve communication between two MDTs and primary care physicians about treatment recommendations made within the meeting (54). By selecting and testing tailored implementation strategies through collaboration with MDT members, consumers and implementation scientists, we were able to successfully introduce and sustain the template as part of standard care.

\section{Strengths and limitations of this review}

The strengths of this review include that we consulted a broad range of literature sources, including updating search terms for an existing systematic review to identify new studies specifically about lung cancer MDC. We introduce implementation science and quality improvement concepts and highlight how the research methods from these disciplines could assist in creating knowledge about the most effective strategies to drive practice change in lung cancer MDC. The limitations include that we did not conduct a systematic review exclusively focused on evidence gaps in implementation. Instead, we have focused on those gaps that require particular attention and indicate how multi-center studies could address these gaps.

\section{Conclusions}

In this review, we have synthesized information from numerous studies and reviews to provide a comprehensive summary of the 'evidence-practice gaps' in the implementation of lung cancer MDC. As MDC is an essential component of quality care, we consider that there are significant opportunities to improve outcomes for people diagnosed with lung cancer through the conduct of high-quality implementation research.

\section{Acknowledgments}

The authors are very grateful to Kate Booth who conducted the literature searches.

Funding: Dr. Elizabeth Fradgley is supported by a Cancer Institute New South Wales Early Career Fellowship.

\section{Footnote}

Provenance and Peer Review: This article was commissioned by the Guest Editor (Emily Stone) for the series "Lung Cancer Multidisciplinary Care" published in Translational Lung Cancer Research. The article was sent for external peer review organized by the Guest Editor and the editorial office.

Conflicts of Interest: All authors have completed the ICMJE uniform disclosure form (available at http://dx.doi. org/10.21037/tlcr.2019.11.32). The series "Lung Cancer Multidisciplinary Care" was commissioned by the editorial office without any funding or sponsorship. The authors have no other conflicts of interest to declare.

Ethical Statement: The authors are accountable for all aspects of the work in ensuring that questions related to the accuracy or integrity of any part of the work are appropriately investigated and resolved.

Open Access Statement: This is an Open Access article distributed in accordance with the Creative Commons Attribution-NonCommercial-NoDerivs 4.0 International License (CC BY-NC-ND 4.0), which permits the noncommercial replication and distribution of the article with the strict proviso that no changes or edits are made and the original work is properly cited (including links to both the formal publication through the relevant DOI and the license). See: https://creativecommons.org/licenses/by-nc-nd/4.0/. 


\section{References}

1. Cancer Australia. All about multidisciplinary care. Available online: http://canceraustralia.gov.au/clinical-best-practice/ multidisciplinary-care/all-about-multidisciplinary-care

2. Walsh J, Harrison JD, Young JM, et al. What are the current barriers to effective cancer care coordination? A qualitative study. BMC Health Serv Res 2010;10:132.

3. Gerteis M, Edgman-Levitan S, Daley J, et al. Through the patient's eyes: understanding and promoting patientcentered care. San Fransisco, USA: Jossey-Bass, 1993.

4. Australian Commission on Safety and Quality in Health Care. Australian Safety and Quality Framework for Health Care. Available online: http://www.safetyandquality. gov.au/national-priorities/australian-safety-and-qualityframework-for-health-care/. Accessed 06/10/2019.

5. Department of Health. The NHS improvement plan: putting people at the heart of public services. London, UK: National Health Service, 2004.

6. Minister of Health. Improving quality (IQ): a systems approach for the New Zealand health and disability sector. Wellington: Ministry of Health, 2003.

7. US Department of Health Human Services. Report to Congress: national strategy for quality improvement in health care. 2011. Available online: https://www.ahrq.gov/ workingforquality/reports/2011-annual-report.html

8. Department of Health. Achieving best practice cancer care: A guide for implementing multidisciplinary care. Melbourne, Victoria: Metropolitan Health and Aged Care Services Division, Victorian Government Department of Human Services, 2007.

9. National Breast Cancer Centre. Multidisciplinary care in Australia: a National Demonstration Project in Breast Cancer: summary report. Camperdown, NSW: National Breast Cancer Centre, 2003.

10. Borras JM, Albreht T, Audisio R, et al. Policy statement on multidisciplinary cancer care. Eur J Cancer 2014;50:475-80.

11. Pillay B, Wootten AC, Crowe H, et al. The impact of multidisciplinary team meetings on patient assessment, management and outcomes in oncology settings: A systematic review of the literature. Cancer Treat Rev 2016;42:56-72.

12. Wilcoxon H, Luxford K, Saunders C, et al. Multidisciplinary cancer care in Australia: A national audit highlights gaps in care and medico-legal risk for clinicians. Asia Pac J Clin Oncol 2011;7:34-40.

13. Osarogiagbon RU, Freeman RK, Krasna MJ.
Implementing effective and sustainable multidisciplinary clinical thoracic oncology programs. Transl Lung Cancer Res 2015;4:448-55.

14. Brar SS, Hong NL, Wright FC. Multidisciplinary cancer care: Does it improve outcomes? J Surg Oncol 2014;110:494-9.

15. Prades J, Remue E, van Hoof E, et al. Is it worth reorganising cancer services on the basis of multidisciplinary teams (MDTs)? A systematic review of the objectives and organisation of MDTs and their impact on patient outcomes. Health Policy 2015;119:464-74.

16. Saini KS, Taylor C, Ramirez AJ, et al. Role of the multidisciplinary team in breast cancer management: results from a large international survey involving 39 countries. Ann Oncol 2012;23:853-9.

17. Bain C, Raikundalia GK, Shulman T, et al. Multidisciplinary Team Meetings for Cancer Care: Results of an Australian Survey. J Cancer Res Ther 2013;1:12-23.

18. Wright FC, Lookhong N, Urbach D, et al. Multidisciplinary Cancer Conferences: Identifying Opportunities to Promote Implementation. Ann Surg Oncol 2009;16:2731-7.

19. Licitra L, Keilholz U, Tahara M, et al. Evaluation of the benefit and use of multidisciplinary teams in the treatment of head and neck cancer. Oral Oncol 2016;59:73-9.

20. Richardson B, Preskitt J, Lichliter W, et al. The effect of multidisciplinary teams for rectal cancer on delivery of care and patient outcome: has the use of multidisciplinary teams for rectal cancer affected the utilization of available resources, proportion of patients meeting the standard of care, and does this translate into changes in patient outcome? Am J Surg 2016;211:46-52.

21. Campbell BA, Ball D, Mornex F. Multidisciplinary lung cancer meetings: improving the practice of radiation oncology and facing future challenges. Respirology 2015;20:192-8.

22. Kelly SL, Jackson JE, Hickey BE, et al. Multidisciplinary clinic care improves adherence to best practice in head and neck cancer. Am J Otolaryngol 2013;34:57-60.

23. Kostaras X, Shea-Budgell MA, Malcolm E, et al. Is there a role for clinical practice guidelines in multidisciplinary tumor board meetings? A descriptive study of knowledge transfer between research and practice. J Cancer Educ 2012;27:42-5.

24. Rowlands S, Callen J. A qualitative analysis of communication between members of a hospital-based multidisciplinary lung cancer team. Eur J Cancer Care (Engl) 2013;22:20-31. 
25. Devitt B, Philip J, McLachlan SA. Team dynamics, decision making, and attitudes toward multidisciplinary cancer meetings: health professionals' perspectives. J Oncol Pract 2010;6:e17-20.

26. Kane B, Luz S. Information Sharing at Multidisciplinary Medical Team Meetings. Group Decision and Negotiation 2011;20:437-64.

27. Russell GK, Jimenez S, Martin L, et al. A multicentre randomised controlled trial of reciprocal lung cancer peer review and supported quality improvement: results from the improving lung cancer outcomes project. Br J Cancer 2014;110:1936.

28. Slavova-Azmanova NS, Johnson CE, Platell C, et al. Peer review of cancer multidisciplinary teams: is it acceptable in Australia? Med J Aust 2015;202:144-7.

29. Bellamy D, Peake M, Williams A. The role of primary care as part of the multidisciplinary team (MDT) in the management of lung cancer: the "Dream MDT" report new guidance from the UK Lung Cancer Coalition. Prim Care Respir J 2013;22:3-4.

30. Taylor C, Finnegan-John J, Green JS. "No decision about me without me" in the context of cancer multidisciplinary team meetings: a qualitative interview study. BMC Health Serv Res 2014;14:488.

31. Tattersall MH. Multidisciplinary team meetings: where is the value? Lancet Oncol 2006;7:886-8.

32. Hamilton DW, Heaven B, Thomson RG, et al. Multidisciplinary team decision-making in cancer and the absent patient: a qualitative study. BMJ Open 2016;6:e012559.

33. Butow P, Harrison JD, Choy ET, et al. Health professional and consumer views on involving breast cancer patients in the multidisciplinary discussion of their disease and treatment plan. Cancer 2007;110:1937-44.

34. Jalil R, Lamb B, Russ S, et al. The cancer multidisciplinary team from the co-ordinators' perspective: results from a national survey in the UK. BMC Health Serv Res 2012;12:457.

35. Kedia SK, Ward KD, Collins AC, et al. "All boats will rise": Physicians' perspectives on multidisciplinary lung cancer care in a community-based hospital setting. Support Care Cancer 2020;28:1765-73.

36. Chinai N, Bintcliffe F, Armstrong EM, et al. Does every patient need to be discussed at a multidisciplinary team meeting? Clin Radiol 2013;68:780-4.

37. De Ieso PB, Coward JI, Letsa I, et al. A study of the decision outcomes and financial costs of multidisciplinary team meetings (MDMs) in oncology. Br J Cancer
2013;109:2295-300.

38. Patkar V, Acosta D, Davidson T, et al. Cancer multidisciplinary team meetings: evidence, challenges, and the role of clinical decision support technology. Int J Breast Cancer 2011;2011:831605.

39. Freeman RK, Ascioti AJ, Dake M, et al. The Effects of a Multidisciplinary Care Conference on the Quality and Cost of Care for Lung Cancer Patients. Ann Thorac Surg 2015;100:1834-8; discussion 1838.

40. Prabhu Das I, Baker M, Altice C, et al. Outcomes of multidisciplinary treatment planning in US cancer care settings. Cancer 2018;124:3656-67.

41. Lamb BW, Brown KF, Nagpal K, et al. Quality of care management decisions by multidisciplinary cancer teams: a systematic review. Ann Surg Oncol 2011;18:2116-25.

42. Soukup T, Lamb BW, Arora S, et al. Successful strategies in implementing a multidisciplinary team working in the care of patients with cancer: an overview and synthesis of the available literature. J Multidiscip Healthc 2018;11:49-61.

43. Ke KM, Blazeby JM, Strong S, et al. Are multidisciplinary teams in secondary care cost-effective? A systematic review of the literature. Cost Eff Resour Alloc 2013;11:7.

44. Stairmand J, Signal L, Sarfati D, et al. Consideration of comorbidity in treatment decision making in multidisciplinary cancer team meetings: a systematic review. Ann Oncol 2015;26:1325-32.

45. Rankin NM, McGregor D, Stone E, et al. Evidencepractice gaps in lung cancer: A scoping review. Eur J Cancer Care (Engl) 2018;27:e12588.

46. Boxer MM, Vinod SK, Shafiq J, et al. Do multidisciplinary team meetings make a difference in the management of lung cancer? Cancer 2011;117:5112-20.

47. Bydder S, Nowak A, Marion K, et al. The impact of case discussion at a multidisciplinary team meeting on the treatment and survival of patients with inoperable nonsmall cell lung cancer. Intern Med J 2009;39:838-41.

48. Freeman RK, Van Woerkom JM, Vyverberg A, et al. The effect of a multidisciplinary thoracic malignancy conference on the treatment of patients with lung cancer. Eur J Cardiothorac Surg 2010;38:1-5.

49. Liam CK, Andarini S, Lee P, et al. Lung cancer staging now and in the future. Respirology 2015;20:526-34.

50. Liu H, Song Y. MDT is still important in the treatment of early stage lung cancer. J Thorac Dis 2018;10:S3984-5.

51. Oudkerk M, Devaraj A, Vliegenthart R, et al. European position statement on lung cancer screening. Lancet Oncol 2017;18:e754-66. 
52. Pan CC, Kung PT, Wang YH, et al. Effects of multidisciplinary team care on the survival of patients with different stages of non-small cell lung cancer: a national cohort study. PLoS One 2015;10:e0126547.

53. Prabhakar CN, Fong KM, Peake MD, et al. The effectiveness of lung cancer MDT and the role of respiratory physicians. Respirology 2015;20:884-8.

54. Rankin NM, Collett GK, Brown CM, et al. Implementation of a lung cancer multidisciplinary team standardised template for reporting to general practitioners: a mixed-method study. BMJ Open 2017;7:e018629.

55. Rivas-Perez H, Nana-Sinkam P. Integrating pulmonary rehabilitation into the multidisciplinary management of lung cancer: a review. Respir Med 2015;109:437-42.

56. Schulkes KJG, Hamaker ME, Lammers JJ, et al. Multidisciplinary decision-making regarding chemotherapy for lung cancer patients-An age-based comparison. Eur J Cancer Care (Engl) 2018. doi: 10.1111/ ecc. 12768.

57. Stevens W, Stevens G, Kolbe J, et al. Management of stages I and II non-small-cell lung cancer in a New Zealand study: divergence from international practice and recommendations. Intern Med J 2008;38:758-68.

58. Stone E, Rankin N, Kerr S, et al. Does presentation at multidisciplinary team meetings improve lung cancer survival? Findings from a consecutive cohort study. Lung Cancer 2018;124:199-204.

59. Stone E, Rankin N, Phillips J, et al. Consensus minimum data set for lung cancer multidisciplinary teams: Results of a Delphi process. Respirology 2018;23:927-34.

60. Ung KA, Campbell BA, Duplan D, et al. Impact of the lung oncology multidisciplinary team meetings on the management of patients with cancer. Asia Pac J Clin Oncol 2016;12:e298-304.

61. Zhang Y, Shen J, Simone CB, 2nd, et al. How to optimize the treatment strategy for patients with EGFRmutant stage IA lung adenocarcinoma: an international multidisciplinary team. J Thorac Dis 2018;10:3883-90.

62. Osarogiagbon RU. "Like heart valve clinic, it probably saves lives, but... Who has time for that?" The challenge of disseminating multidisciplinary cancer care in the United States. Cancer 2018;124:3634-7.

63. Hahlweg P, Hoffmann J, Härter M, et al. In Absentia: An Exploratory Study of How Patients Are Considered in Multidisciplinary Cancer Team Meetings. PLoS One 2015;10:e0139921.

64. Lamb BW, Sevdalis N, Mostafid H, et al. Quality improvement in multidisciplinary cancer teams: an investigation of teamwork and clinical decision-making and cross-validation of assessments. Ann Surg Oncol 2011;18:3535-43.

65. Coulter A, Fitzpatrick R, Cornwell J. Measures of patients' experience in hospital: purpose, methods and uses. London, UK: King's Fund, 2009.

66. Draper M, Cohen P, Buchan H. Seeking consumer views: what use are results of hospital patient satisfaction surveys? Int J Qual Health Care 2001;13:463-8.

67. Shaw C, Organization WH. How can hospital performance be measured and monitored? World Health Organization Regional Office for Europe, 2003.

68. Moloczij N, Gough K, Solomon B, et al. Development of a hospital-based patient-reported outcome framework for lung cancer patients: a study protocol. Health Qual Life Outcomes 2018;16:10.

69. Forrest LM, McMillan DC, McArdle CS, et al. An evaluation of the impact of a multidisciplinary team, in a single centre, on treatment and survival in patients with inoperable non-small-cell lung cancer. Br J Cancer 2005;93:977-8.

70. Munro A, Brown M, Niblock P, et al. Do Multidisciplinary Team (MDT) processes influence survival in patients with colorectal cancer? A population-based experience. BMC Cancer 2015;15:686.

71. Ryan J, Faragher I. Not all patients need to be discussed in a colorectal cancer MDT meeting. Colorectal Dis 2014;16:520-6.

72. Leo F, Venissac N, Poudenx M, et al. Multidisciplinary management of lung cancer: how to test its efficacy? J Thorac Oncol 2007;2:69-72.

73. Rankin NM, Lai M, Miller D, et al. Cancer multidisciplinary team meetings in practice: Results from a multi-institutional quantitative survey and implications for policy change. Asia Pac J Clin Oncol 2018;14:74-83.

74. Tanvetyanon T, Lee JH, Fulp WJ, et al. Changes in the care of non-small-cell lung cancer after audit and feedback: the Florida initiative for quality cancer care. J Oncol Pract 2014;10:e247-54.

75. Intercollegiate Cancer Committee. Educational Initiatives to Improve the Effectiveness of Cancer Multidisciplinary Teams. London: Academy of Medical Royal Colleges, 2009.

76. El Saghir NS, Charara RN, Kreidieh FY, et al. Global Practice and Efficiency of Multidisciplinary Tumor Boards: Results of an American Society of Clinical Oncology International Survey. J Glob Oncol 2015;1:57-64. 
77. Charara RN, Kreidieh FY, Farhat RA, et al. Practice and Impact of Multidisciplinary Tumor Boards on Patient Management: A Prospective Study. J Glob Oncol 2016;3:242-9.

78. Cancer Australia. All about multidisciplinary care. Available online: https://canceraustralia.gov.au/ clinical-best-practice/multidisciplinary-care/all-aboutmultidisciplinary-care. Cancer Australia, Sydney, Australia, 2019.

79. Miech EJ, Rattray NA, Flanagan ME, et al. Inside help: An integrative review of champions in healthcare-related implementation. SAGE Open Med 2018;6:2050312118773261.

80. Lamb B, Payne H, Vincent C, et al. The role of oncologists in multidisciplinary cancer teams in the UK: an untapped resource for team leadership? J Eval Clin Pract 2011;17:1200-6.

81. Lennes IT, Lynch TJ. Quality Indicators in Cancer Care: Development and Implementation for Improved Health Outcomes in Non-Small-Cell Lung Cancer. Clinical Lung Cancer 2009; 10:341-6.

82. Lawrence M, Olesen F. Indicators of Quality in Health Care. Eur J Gen Pract 1997;3:103-8.

83. Ouwens MM, Hermens RR, Termeer RA, et al. Quality of integrated care for patients with nonsmall cell lung cancer: variations and determinants of care. Cancer 2007;110:1782-90.

84. Tanvetyanon T. Quality-of-care indicators for non-small cell lung cancer. Cancer Control 2009;16:335-41.

85. Blum TG, Rich A, Baldwin D, et al. The European initiative for quality management in lung cancer care. Eur Respir J 2014;43:1254-77.

86. Wang X, Su S, Li S, et al. Development of quality indicators for non-small cell lung cancer care: a first step toward assessing and improving quality of cancer care in China. BMC cancer 2017;17:603.

87. Taylor C, Munro AJ, Glynne-Jones R, et al. Multidisciplinary team working in cancer: what is the evidence? BMJ 2010;340:c951.

88. Bjegovich-Weidman M, Haid M, Kumar S, et al. Establishing a community-based lung cancer multidisciplinary clinic as part of a large integrated health care system: aurora health care. J Oncol Pract 2010;6:e27-30.

89. Voong KR, Liang OS, Dugan P, et al. Thoracic Oncology Multidisciplinary Clinic Reduces Unnecessary Health Care Expenditure Used in the Workup of Patients With Non-small-cell Lung Cancer. Clin Lung Cancer 2019;20:e430-41.

90. Jakobsen E, Rasmussen TR. The Danish Lung Cancer Registry. Clin Epidemiol 2016;8:537-41.

91. Jakobsen E, Green A, Oesterlind K, et al. Nationwide Quality Improvement in Lung Cancer Care: The Role of the Danish Lung Cancer Group and Registry. J Thorac Oncol 2013;8:1238-47.

92. Stirling RG, Evans SM, McLaughlin P, et al. The Victorian Lung Cancer Registry pilot: improving the quality of lung cancer care through the use of a disease quality registry. Lung 2014;192:749-58.

93. Beck N, Hoeijmakers F, Wiegman EM, et al. Lessons learned from the Dutch Institute for Clinical Auditing: the Dutch model for quality assurance in lung cancer treatment. J Thorac Dis 2018;10:S3472-85.

94. Heineman DJ, Ten Berge MG, Daniels JM, et al. The Quality of Staging Non-Small Cell Lung Cancer in the Netherlands: Data From the Dutch Lung Surgery Audit. Ann Thorac Surg 2016;102:1622-9.

95. Fung-Kee-Fung M, Maziak DE, Pantarotto JR, et al. Regional process redesign of lung cancer care: a learning health system pilot project. Curr Oncol 2018;25:59-66.

96. Aydinguel O, Jussupow E, Spohrer K, et al. Designing a Mobile Application for Ad-Hoc Tumor Board Scheduling. Research-in-Progress Paper 70. Available online: https:// aisel.aisnet.org/ecis2018_rip/70

97. Brownson RC, Colditz GA, Proctor EK. Dissemination and Implementation Research in Health. New York: Oxford, 2017.

98. Eccles MP, Mittman BS. Welcome to Implementation Science. Implement Sci 2006. doi:10.1186/1748-5908-1-1.

99. Rabin BA, Brownson RC, Haire-Joshu D, et al. A Glossary for Dissemination and Implementation Research in Health. J Public Health Manag Pract 2008;14:117-23.

100. Rabin BA, Brownson RC. Terminology for Dissemination and Implementation Research. In: Brownson RC, Colditz G, Proctor E, editors. Dissemination and Implementation Research in Health: Translating Science to Practice. New York: Oxford, 2017.

101. Bauer MS, Damschroder L, Hagedorn H, et al. An introduction to implementation science for the nonspecialist. BMC Psychology 2015;3:32.

102. Livet M, Haines ST, Curran GM, et al. Implementation Science to Advance Care Delivery: A Primer for Pharmacists and Other Health Professionals. Pharmacotherapy 2018;38:490-502.

103. Proctor EK, Powell BJ, Baumann AA, et al. Writing implementation research grant proposals: ten key 
ingredients. Implement Sci 2012;7:96.

104. May CR, Johnson M, Finch T. Implementation, context and complexity. Implement Sci 2016;11:141.

105.Pinnock H, Barwick M, Carpenter CR, et al. Standards for Reporting Implementation Studies (StaRI) Statement. BMJ 2017;356:16795.

106. Effective Practice and Organisation of Care. Effective Practice and Organisation of Care (EPOC) Taxonomy. Available online: https://epoc.cochrane.org/epoctaxonomy

107.Powell BJ, Waltz TJ, Chinman MJ, et al. A refined compilation of implementation strategies: results from the Expert Recommendations for Implementing Change (ERIC) project. Implement Sci 2015;10:21.

108. Grimshaw JM, Eccles MP, Lavis JN, et al. Knowledge translation of research findings. Implement Sci 2012;7:50.

109. Powell BJ, Fernandez ME, Williams NJ, et al. Enhancing the Impact of Implementation Strategies in Healthcare: A Research Agenda. Front Public Health 2019;7:3.

110. Taylor MJ, McNicholas C, Nicolay C, et al. Systematic

Cite this article as: Rankin NM, Fradgley EA, Barnes DJ. Implementation of lung cancer multidisciplinary teams: a review of evidence-practice gaps. Transl Lung Cancer Res 2020;9(4):16671679. doi: 10.21037/tlcr.2019.11.32 review of the application of the plan-do-study-act method to improve quality in healthcare. BMJ Qual Saf 2014;23:290-8.

111. Nicolay CR, Purkayastha S, Greenhalgh A, et al. Systematic review of the application of quality improvement methodologies from the manufacturing industry to surgical healthcare. Br J Surg 2012;99:324-35.

112. Wells S, Tamir O, Gray J, et al. Are quality improvement collaboratives effective? A systematic review. BMJ Qual Saf 2018;27:226-40.

113. Iyer NG, Chua MLK. Multidisciplinary team meetings challenges of implementation science. Nat Rev Clin Oncol 2019;16:205-6.

114. Fradgley EA, Karnon J, Roach D, et al. Taking the pulse of the health services research community: a cross-sectional survey of research impact, barriers and support. Aust Health Rev 2020;44:160-7.

115. Boaz A, Hanney S, Borst R, et al. How to engage stakeholders in research: design principles to support improvement. Health Res Policy Syst 2018;16:60. 